\section{ARCTIC GEOLOGY}

Busin Drifi

from our Structural Geology Correspondent

THE declared theme of the symposium on Arctic geology, organized by the American Association of Petroleum Geologists and held in San Francisco during February 1-4, was the regional geology of the Arctic. This subject was convincingly and comprehensively covered by some thirty contributors, but most interest was perhaps aroused by the discussions of petroleum exploration and the evolution of the Arctic Ocean Basin.

At the time of the 1960 symposium ideas of seafloor spreading and the associated concept of plate tectonics were in their infancy. Consequently many of the earlier hypotheses for the evolution of the Arctic Ocean Basin have had to be substantially modified. As pointed out by Dr N. A. Ostenso (Office of Naval Research, Arlington), the unique situation of the Arctic Ocean, bordered by both the New and Old Worlds and linking the Atlantic Ocean with the Pacific Ocean, presents a key to understanding not only the present spreading movements but possibly also the older plate arrangements.

The Arctic Ocean consists of two distinct oceanic basins-the Eurasia Basin and the Canada Basin, separated by a strip of continental crust, the Lomonosov Ridge. The Eurasia Basin was shown by means of symmetrical magnetic anomaly striping to have opened during the past 30 million years; its central spreading ridge was connected by means of the De Geer transform fault to the mid-Atlantic spreading ridge. The Lomonosov Ridge would thus represent a piece of the Barents Shelf carried westwards by spreading. The Canada Basin seems to be an older oceanic basin with no pronounced magnetic striping. Views concerning its origin were varied, but most speakers, including Dr I. L. Tailleur (US Geological Survey), favoured its opening during - Late Mesozoic by means of a pivotal action about the Alaskan Orocline which would have involved the rotation of Alaska away from the Arctic Canadian Islands, a situation well substantiated by surface geology.

Baffin Bay and its connexion by way of the Davis Straits to the Labrador Sea and the Atlantic was shown (J. W. Kerr (Geological Survey of Canada), and others) to have opened by the drift of Greenland away from Baffin Island pivoted on Ellesmere Island in the Canadian Arctic. Thus the present Arctic Basin seems to have developed during the most recent stages of seafloor spreading, in contrast with the Pacific which it would seem presents a constant physiogeographic feature at least since the beginning of Phanerozoic time.
Measuring the Invisible

FIFTY years ago a distinguished RollsRoyce engineer, A. A. Griffith, postulated an explanation for the fact that the tensile fracture strength of brittle solids such as glass is surprisingly low and moreover statistically very variable. $\mathrm{He}$ proposed that the surface is pitted by many submicroscopic cracks which can locally amplify an applied stress.

Circumstantial evidence has long since established Griffith's hypothesis beyond all cavil. Practical improvements in the strength of glass and other brittle materials have been based on Griffith's recognition that the surface determines strength; strength can be increased by either removing the cracks through etching or otherwise, and at once protecting the surface by means of a hard coating, or by prestressing a thin surface layer in compression.

Throughout all such technological developments, Griffith's microcracks have remained shadowy entities, apprehended but not seen. A number of methods have been tried to make them visible: plenty of cracks were revealed, but there are reasons for believing that the treatment may create more new cracks than it enlarges old ones.

Next Monday's issue of Nature Physical Science includes an article by J. D. Poloniecki and T. R. Wilshaw which establishes a new way of tackling the problem. The technique is the Hertzian fracture test. A hard sphere (here a tungsten carbide ball $0.77 \mathrm{~mm}$ in diameter) is pressed into the glass surface under continuous observation until a ring crack suddenly spreads and grows concentrically with the indentation. The radius of this crack, $r_{c}$, and the load $P$ at which it forms are recorded, and the test is repeated many times. The ring radius and critical load are related to the surface density of microcracks of various depths, and therefore in principle it is possible, from distributions of $r_{\mathrm{c}}$ and $P$, to deduce histograms of surface densities of cracks as a function of crack-depth. This has been recognized for some years, but the problem has been to find an acceptable way of analysing the data statistically. Most previous investigators have been content to postulate a particular form for the histogram (a "Weibull distribution"), which prejudges the central issue. Moreover, nobody has proposed simultaneous analysis of the distributions of both $r_{\mathrm{c}}$ and $P$.

Poloniecki and Wilshaw's investigation is the outcome of a collaboration between a fracture mechanics expert and a statistician, and it now seems that the analytical problem has been solved. The critical step is to assess the surface area "at risk" in each individual test, and to sum these for all the tests: this total area at risk is different according to the particular range of crack depth under assessment, and has to be separately estimated for each bar of the histogram. The technique has been applied to mechanically polished silica glass and a $\log / \log$ histogram produced, complete with 90 per cent confidence limits.

\title{
Source Counts and Astronomical Evolution
}

THE game of counting astronomical sources as a function of brightness to test whether they are distributed uniformly throughout space seems to have been invented by Newton.

In the 1960 s, the radio astronomers, after a false start based on the ill-starred second (2C) Cambridge catalogue, agreed that they had shot down the steady state theory with radio source counts. The $4 \mathrm{C}$ and $5 \mathrm{C}$ surveys showed, however, that the unexpectedly steep increase in the number of sources with decreasing brightness did not continue indefinitely, and in fact were at first interpreted as implying that we had seen right back to the epoch at which the galaxies giving rise to the radio emission were formed. This would have been a spectacular result, but unfortunately turned out not to be the only possible interpretation of the source counts.

When the results of the deep Cambridge surveys were confirmed by counts performed by the radio astronomy group at Bologna, it looked as if the observational situation, at least, was sewn up. A cloud appeared on the horizon recently in the form of counts of 8,100 sources surveyed by the group at Ohio
State University (Harris, Beverly and Kraus, Nature, 227, 785; 1970). The OHS surveys were done at a slightly different frequency to those at Cambridge and Bologna $(1,415 \mathrm{MHz}$ instead of 408 ), but on conversion they gave significantly fewer faint sources than the latter, though agreeing in the number of bright sources.

In next Monday's Nature Physical Science Jauncey and Neill of Cornell University describe some observations which seem to clear up the discordance. Using the NRAO 300 foot dish, which at $1,400 \mathrm{MHz}$ has considerably better resolution and sensitivity than the OHS instrument, they have checked the OHS flux density scale. They found that the random errors are greater than those quoted (which would tend to increase the number of faint sources found) and, more importantly, that the flux densities of the weaker sources are systematically underestimated. This latter bias was confirmed by comparing the OHS catalogue with others done at the same frequency at $\mathrm{Cal} \mathrm{Tec}$ and at Parkes. Correcting for the bias brought the source counts into agreement with the Cambridge and Bologna counts. 